\title{
Letter to Editor Concerning the Article "Use of General Surgery and Urology Online Modules in Medical Education"
}

\author{
Manoosh Mehrabi ${ }^{1, *}$ \\ ${ }^{1}$ Center of Excellence for E-Learning, Shiraz University of Medical Sciences, Shiraz, IR Iran \\ "Corresponding author: Manoosh Mehrabi, Center of Excellence for E-Learning, Shiraz University of Medical Sciences, Shiraz, IR Iran. Tel: +98-7132300037, E-mail: \\ mehrabi.manoosh@gmail.com
}

Received 2016 May 31; Accepted 2016 May 31.

Keywords: General Surgery, General Surgery, General Surgery, Medical Education

\section{Dear Editor,}

Greetings and thanks for the publication of the valuable article: "Use of General Surgery and Urology Online Modules in Medical Education" (1). E-learning has now become an absolute necessity for the world's progressive universities, and we read this article with interest and found it very strong and evidence-based. I would like to raise two points that may be of interest to the authors and your readership:

1. No Significant Difference Phenomenon

2. Teaching skills in e-learning

\section{No Significant Difference Phenomenon}

No Significant Difference Phenomenon is a book written in 1999 by Thomas Russell from the university of North Carolina-America, in which the author gathered findings from various studies conducted between 1928 and 1998 on the efficacy of technology compared to other methods. He found 355 research reports, abstracts and articles in which the study groups had no significant difference, and proposed that there are very few studies that show greater efficacy and significant difference in education by using different kinds of technology compared to other teaching methods. The book emphasizes that teachers had better focus on effective learning rather than technology (2). A metaanalysis conducted in 2015 concluded that e-learning and traditional methods are equally effective (3).

\section{Teaching Skills in E-learning}

The second issue is teaching skills in e-learning. In his book "Instructional Design for e-Learning" in 2013, Arshavskiy writes:

"Even though e-learning is a popular solution for many performance problems, it is mostly appropriate for increasing knowledge and developing cognitive skills. Even if the course follows the most solid instructional design principles, it cannot teach people how to drive a car for example, because driving is a psychomotor skill, which requires real-life practice for best result"; and continues by recommending use of a combined method to change the attitude and behavior of the learner, which should include educational games, simulations and role-play (4).

\section{Conclusion}

We believe that the choice of online, offline, or blended learning, using various technologies or traditional methods should emerge from the heart of instructional design. Furthermore, it is essential for detailed and proper instructional design studies based on analysis of the needs, audiences, gaps, responsibilities and objectives to be first conducted, so that the best method can emerge. In the meantime, care should be taken in use of e-learning in subjects associated with psychomotor domain.

\section{References}

1. Chang D, McCombie S, Logan C, Davine A, Leece F, Jonas-Dwyer D, et al. Use of General Surgery and Urology Online Modules in Medical Education. Ann Colorectal Res. 2016;4(1) doi:10.17795/acr-33450.

2. Russell TL. The no significant difference phenomenon: A comparative research annotated bibliography on technology for distance education: As reported in 355 research reports, summaries and papers. Carolina: North Carolina State University; 1999.

3. Nguyen T. The effectiveness of online learning: Beyond no significant difference and future horizons. MERLOT J Online Learn Teach. 2015;11(2):309-19.

4. Arshavskiy M. Instructional design for elearning: essential guide to creating successful elearning courses. United States: Your ELearning World; 2013. 